\title{
Giovanna Colombetti
}

Department of Sociology, Philosophy, and Anthropology

University of Exeter

Amory, Rennes Drive

Exeter EX4 4RJ

G DOT Colombetti AT exeter DOT ac DOT UK

\section{Enactive affectivity, extended}

\begin{abstract}
In this paper I advance an enactive view of affectivity that does not imply that affectivity must stop at the boundaries of the organism. I first review the enactive notion of "sense-making", and argue that it entails that cognition is inherently affective. Then I review the proposal, advanced by Di Paolo (2009), that the enactive approach allows living systems to "extend". Drawing out the implications of this proposal, I argue that, if enactivism allows living systems to extend, then it must also allow sense-making, and thus cognition as well as affectivity, to extend-in the specific sense of allowing the physical processes (vehicles) underpinning these phenomena to include, as constitutive parts, non-organic environmental processes. Finally I suggest that enactivism might also allow specific human affective states, such as moods, to extend.
\end{abstract}

\section{Introduction}

Affectivity — broadly construed to include emotions, moods, and motivational states (such as desires, needs, fatigue, pain) - is typically regarded as a state of the organism, a state the organism "is in". Scholars disagree on what components are necessary for affective states, but whatever components they include, these are usually states or processes that remain within the organism. Some theories, for example, regard emotional episodes as usually involving bodily processes, such as facial expressions or patterns of activation of the autonomic nervous 
system (e.g., James 1884; Damasio 1999; Prinz 2004). On the other hand, cognitive theories see emotions as cognitive states or processes (Solomon 1993; Nussbaum 2004); given that cognition is usually seen as underpinned by brain processes, in the absence of further qualifications these theories thus favour the brain (or even some part of it) as the seat of emotions. In spite of their differences, these approaches are all internalist, in the sense that they conceive of emotions as underpinned by material processes, or "vehicles", located inside the organism. ${ }^{1}$ Although existing theoretical discussions of moods and motivational states are less developed and systematic, it is fair to say that these states are also typically regarded as underpinned by material processes that remain within the organism.

In this paper I challenge this mainstream internalist framework, and argue that it is possible to conceive of affective states as underpinned not only by organic processes, but also by hybrid processes involving organic and non-organic elements. In this sense, I defend an externalist view of affectivity. I do so, however, not by drawing on the influential Hypothesis of Extended Cognition (HEC), but from the perspective of the "enactive" approach originally advanced by Varela, Thompson and Rosch (1991), and further developed by Thompson (2007, 2011) and others (e.g., Di Paolo 2005). ${ }^{2}$ It has been argued (see Wheeler 2010) that enactivism entails an internalist view of the mind, and that it is therefore incompatible with HEC. In this paper I offer a different view. I do not deny that HEC and the enactive approach provide contrasting accounts of the nature of the mental, but I argue that enactivism is not internalist. Rather, it is possible to identify cases in which, from an enactive perspective, physical processes outside the organism ought to be regarded as vehicles of mental processes. It is thus possible to say that the enactive mind also "extends"-although, as we shall see, on

\footnotetext{
${ }^{1}$ There are different versions of both internalism and externalism (see Hurley 2010). In this paper I am concerned only with "vehicle" internalism/externalism (as opposed to "content" internalism/externalism), which is about the location of the material vehicles taken to underpin mental states. I also adopt a relatively broad characterization of internalism, according to which vehicles outside the brain but within the organism still count as internal (whereas sometimes internalism is limited to the view that the vehicles of mental states are "brainbound", i.e., remain within the brain).

2 In recent years, the term "enactivism" has come to refer to a variety of related but different approaches - such as Noë’s (2004) “dynamic sensorimotor approach”, and Hutto and Myin's (2013) "radical enactivism". For the purposes of this paper I focus on the canonical version of enactivism, and in particular on its account of the relationship between life and mind.
} 
the basis of different criteria from those posited by HEC. More specifically, in this paper I aim to show that enactivism allows not just cognition, but also affectivity, to extend. If my arguments are on the right track, they will illustrate at least one way in which one can challenge the traditional internalist view of affectivity. ${ }^{3}$

The paper is organized as follows. In section 2 I first review the enactive idea that cognition is sense-making, and then argue that this idea entails that cognition is inherently affective. In section $3 \mathrm{I}$ turn to the charge that enactivism entails an internalist view of cognition, and review how enactivists have replied to this charge. In particular I focus on the proposal that living systems can extend by allowing "mediating structures" into their organization (Di Paolo 2009). In section 4 I draw out the implications of this proposal, arguing that, if from an enactive perspective life can extend, then sense-making can too, and with it cognition and affectivity (enactively characterized). I then go on to illustrate this view in more detail at the phenomenological level, with reference to the notions of Umwelt and affordances. Finally, in section 5 I offer some (very) preliminary ideas on how the considerations developed previously may apply to human moods.

\section{Enactive affectivity}

We need first of all to clarify the enactive perspective on affectivity. ${ }^{4}$ This clarification requires introducing the enactive notion of sense-making, which in turn requires explicating the related notions of autonomy and adaptivity. As we will see, enactivism holds that all living organisms, as autonomous and adaptive, are sense-making systems and that, as such, they are cognitive. Sense-making, in other words, is "the basic mark of the cognitive" (Thompson 2011: 211). In this section I first provide a summary of the arguments behind this proposal, ${ }^{5}$ and then argue that the enactive notion of sense-making entails that living organisms are not only cognitive, but simultaneously also affective.

\footnotetext{
${ }^{3}$ For different ways of challenging this view, see Stephan, Walter and Wilutzky (2014) and Colombetti and Roberts (2015) on how HEC can be applied to the affective domain.

${ }^{4}$ In what follows I summarize my own viewpoint (see Colombetti 2010, 2014). Other relevant discussions can be found in Varela and Depraz (2005), and Thompson (2007, chapter 12). Not much otherwise has been written about affectivity from an enactive perspective.

${ }^{5}$ Thompson and Stapleton (2009) and Di Paolo and Thompson (2014) also provide useful succinct introductions. For the full treatment, see Thompson (2007).
} 
Let us begin, then, with the enactive conception of autonomy. This notion has its roots in Maturana and Varela's (1980) theory of autopoiesis (first published in Spanish in 1972), and was developed further by Varela (1979). Maturana and Varela aimed first and foremost to provide an operational characterization of life. Living systems, they proposed, are physical autopoietic systems (or autopoietic "machines"), i.e., literally, physical self-making systems. In their definition, an autopoietic system is

A network of processes of production (transformation and destruction) of components that produces the components which: (i) through their interactions and transformations continuously regenerate the network of processes (relations) that produced them; and (ii) constitute it (the machine) as a concrete unity in the space in which they (the components) exist by specifying the topological domain of its realization as such a network. (Maturana and Varela 1980: 79)

This characterization was meant to be formal, like the one of a Turing machine. Maturana and Varela then went on to characterize living systems as physical instantiations of autopoietic machines. The paradigmatic physical autopoietic system is the living cell. A cell is a network of interacting processes of production that continually regenerates itself and that constitutes itself as a unity (self-identifies). In a further section of their work, Maturana and Varela also stated that living systems, as autopoietic, are cognitive systems: "The domain of all the interactions in which an autopoietic system can enter without loss of identity is its cognitive domain" (199).

It is undeniable that these elements of the theory of autopoiesis have influenced the enactive approach. However, recent developments of the latter have also distanced themselves from the original formulation of this theory, modifying parts of it, adding various qualifications, and developing it in new directions. ${ }^{6}$ One shift has been the abandonment of the distinction between physical and abstract (formal) autopoietic systems, and its replacement with the distinction between autopoietic systems and (formally defined) autonomous systems. In Varela's (1979: 15) characterization, autopoiesis is "one possible form of autonomy", and the term should be restricted to systems (natural or artificial) characterized by a chemical network (or something very close to it). He also maintained that

\footnotetext{
${ }^{6}$ It is thus not exact to call this strand of enactivism "autopoietic", as Hutto and Myin (2013) do. Note also that the theory of autopoiesis does not feature in Varela et al. (1991).
} 
the idea of autopoiesis is "restricted to relations of production of some kind, and refers to topological boundaries" (54). This characterization does not apply to systems that lack these relations and boundaries, but that nevertheless can be said to exhibit autonomy, such as insect societies (ibid.). Similarly, Thompson (2007: 44) characterizes autopoietic systems as instantiations of autonomous systems in the chemical domain, and points out that whereas all autopoietic systems have an autonomous organization, not all autonomous systems are autopoietic (e.g., complex living systems such as multicellular metazoan systems, nervous systems, insect colonies are autonomous but not autopoietic).

What, then, are autonomous systems? Thompson (2007: 44) defines them as systems whose constituent processes "(i) recursively depend on each other for their generation and their realization as a network, (ii) constitute the system as a unity in whatever domain they exist, and (iii) determine a domain of possible interactions with the environment". This definition entails that autonomous systems are operationally closed. Operational closure refers to a specific kind of organization in which the results of the operations performed by the constituents of the system remain within the system itself. Importantly, an operationally closed system is not causally isolated from its surroundings; it can still be influenced by, and influence, processes that are not part of it.

Operational closure is necessary for autonomy; however, as Di Paolo and Thompson (2014) have recently emphasized, it is not sufficient. Some systems, like cellular automata, are operationally closed but not autonomous in the "wider sense" Di Paolo and Thompson want - where this wider sense needs to include also "implications conveyed by notions such as 'spontaneity,' 'immanent purposiveness,' 'intrinsic teleology', and the 'self-generation of norms" (71-72). Here is where precariousness enters the story. A component process of an operationally closed network is precarious if it stops, runs down or ceases to exist in the absence of the enabling relations established by the network. The point Di Paolo and Thompson want to make is that only a network of precarious processes can be "literally selfenabling" (72), because only such a network would have to continually work to maintain itself, to counteract the unstable and decaying nature of its processes. And the "restless" (ibid.) character of such a network is also what makes the network seek interactions with its surroundings, to get the necessary energetic and material resources.

In sum, then, recent versions of enactivism define autonomy in terms of operational closure and precariousness. The next step towards the enactive characterization of sensemaking is provided by the notion of adaptivity. Adaptivity refers to the capacity of certain autonomous systems to regulate themselves with respect to conditions registered as improving 
or deteriorating, viable or unviable (Di Paolo 2005). To take a much-cited example, think of a motile bacterium that, to maintain itself, swims toward higher concentrations of sugar and away from noxious substances. In doing so, it regulates its network of processes with respect to its conditions, registered as unviable (when the system meets the noxious substance) or as viable (when the system meets the higher concentrations of sugar). Importantly, enactivism emphasizes that this regulation is at the same time an evaluation of the system's surroundings, in the sense that, as the system regulates its conditions of viability, its surroundings acquire meaning for it: the noxious substance is for the bacterium something to be avoided, and more sugar is something to be sought. This process of evaluation, which is made possible by the autonomous and adaptive nature of living organisms, is what enactivists call sense-making. It entails the transformation of the physiochemical environment of the organism into an Umwelt: a world that is meaningful for the organism. ${ }^{7}$ This process, enactivists hold, is already a form of cognition - although a basic one. ${ }^{8}$ It is a form of cognition because it entails the appearance of a perspective or point of view on the side of the organism, from which its surroundings have meaning. As Varela (1991: 85) stressed, we have to posit such a point of view if we want to make any sense of the bacterium's behaviour:

The entire bacterium points to [its sucrose gradient and flagellar beat] as relevant: the specific significance as components of feeding behavior is only possible by the presence and perspective of the bacterium as a totality. Remove the bacterium as a unity, and all correlations between gradients and hydrodynamic properties become

\footnotetext{
${ }^{7}$ The term "Umwelt" as is used here comes from Jacob von Uexküll (1934/2010), where it refers to the world from the perspective of living organisms that inhabit it, or their "lived environment". Uexküll distinguished between Umwelt and Umgebung, where the latter refers to the physical surroundings of the organism. Varela (1991) draws a parallel distinction between the "world" that is enacted or brought forth by the organism in sense-making, and the physiochemical "environment" in which the organism is situated. In this and other earlier works, Varela used the term "world-making" (rather than "sense-making") to refer to the process of enacting a world of meaning.

${ }^{8}$ The qualification "basic" (Thompson 2011: 211; Di Paolo and Thompson 2014: 73) is meant to allow for the appearance of more complex forms of cognition in more complex organisms, including forms of human cognition dependent on organisms being situated in cultural symbolic contexts.
} 
environmental chemical laws, evident to us as observers but devoid of any special significance.

Varela also talked of "a surplus of signification" (86) to refer to the supplementary meaning that is generated by any living organism's activity of sense-making, as the physical world becomes a meaningful environment for it. The generation (enactment) of this supplementary meaning is a cognitive activity.

This account thus departs significantly from the one provided by approaches in cognitive science and analytic philosophy of mind that characterize cognition as a computational process operating over representational items. For present purposes, an important consequence of the enactive characterization of cognition as sense-making is that cognition turns out to be, from its roots, intrinsically affective, and accordingly that there are no cognitive systems that are not at the same time also affective. By "affective" here I do not mean necessarily "emotional", where "emotion" refers to the capacity to experience or manifest specific "emotions" (fear, anger, joy, envy, sadness, pride, and so on). I mean something more general, which can be characterized as a lack of indifference, and rather a sensibility, interest, or concern for one's existence. This characterization is consistent with the etymology of the term: "affectivity" refers to the capacity or possibility to be done something, to be struck or influenced (the term comes from the past participle of the Latin verb afficio, "to strike, to influence"-itself a compound of $a d$, "to", and facio, "to do"). This influence is not merely physical or mechanical (as when one says that the daily amount of sunlight affects the air temperature) but psychological. It refers to the capacity to be personally affected, to be "touched" in a meaningful way by what is affecting one. In this broad sense, it is not necessary to be in a specific emotion or mood to be in an affective state; one is affected when something merely strikes one as meaningful, relevant, or salient.

Assuming this characterization of affectivity, it should be straightforward to see that sense-making is not just a cognitive but also an affective phenomenon. Sense-making, as we just saw, is the enactment of an Umwelt, and the Umwelt is not just the physical surrounding with which the organism interacts and from which it differentiates itself (in Uexküll's terminology, it is not just an "Umgebung"). The Umwelt is the world from the perspective of the organism; in sense-making, the physical world is transformed into a world of significance for the organism. Thus, the organism is not, and cannot, be indifferent to its Umwelt. The Umwelt is by definition the world as it is relevant for the organism, as it touches, strikes or affects the organism as significant. 
Another way to draw out the affective character of enactive sense-making is with reference to the claim that the perspective of living beings is concerned (Weber and Varela 2002; Di Paolo 2005; Thompson 2007: 152-162). Enactivists explicitly import this idea from Jonas (1966), together with his notion of the immanent purposiveness of living beings. Briefly, since Weber and Varela (2002) enactivists have depicted living organisms as having natural purposes immanent to their organization. A primary natural purpose of organisms is to maintain themselves, to keep being, to "affirm life" (op. cit., 117). This purpose is not imposed from the outside but is intrinsic to the self-maintaining organization of the living system. Thanks to their adaptive nature, living systems also have more specific purposes depending on their structure (the bacterium will aim to get more sugar, for example, because of the way its metabolism is realized) and on the structure of their surroundings (the sugar gradient must contain different concentrations of sugar for the bacterium to move in it). Because of this immanent purposiveness, Weber and Varela talk of the organism as being an "autonomous centre of concern" (98); the precarious nature of life entails that "it is always menaced by concern (Sorge), the need to avoid perishing" (113). As Thompson (2007: 153) puts it,

The organism's 'concern,' its 'natural purpose,' is to keep on going, to continue living, to affirm and reaffirm itself in the face of imminent not-being. Incessant material turnover and exchange with the environment is both a reason for this concern and the only way to meet it. Such is the immanent teleology of life.

The proposal, note, is not that simple organisms such as bacteria experience concern as we or other animals do. There is little reason to believe that bacteria are phenomenally or even prereflectively conscious (see Thompson 2007: 162). The notion of concern at stake here is meant to make the point that living beings are not indifferent to their existence (in the way that a stone for example is). Rather they strive to maintain themselves, and this striving sets them apart from non-living things. Here is where, again, the affective dimension of enactive sense-making should be apparent. The notions of concern and natural purposes denote affective characteristics, an interest of living systems for their existence, a basic sensitivity or “irritability"— to keep to Jonas's terminology.

\footnotetext{
${ }^{9}$ Jonas (1966: 99) talked of the irritability of life to refer to its "sensitiveness to the stimulus", and wrote that "irritability is the germ, as it were the atom, of having a world".
} 


\section{Extending life}

A question raised in recent years about the enactive approach is whether or not it is compatible with HEC (Hypothesis of Extended Cognition), according to which under certain circumstances the material vehicles that underpin cognition need to be located not just in the brain, or even the body, but also in the material environment. This thesis was originally formulated by Clark and Chalmers (1998) and has been further elaborated in subsequent works by Clark (e.g., 2003, 2008) and others (see for example the papers collected in Menary 2010).

According to Wheeler (2010), enactivism and HEC are not compatible. This is because, in his view, enactivism entails that cognition and life are co-located: the boundaries of the living organism are also the boundaries of the cognitive system; because the living system cannot extend (Wheeler takes this to be a "highly plausible claim", p. 35, emphasis in original), the cognitive system cannot either. According to Wheeler, then, enactivism remains an internalist position; even though it entails that cognition is not just in the skull, it does not allow cognition to spill over into the world.

Enactivists have responded to Wheeler (see Di Paolo 2009; Thompson and Stapleton 2009; Thompson 2011), pointing out that whereas there are undeniable tensions between enactivism and HEC, enactivism is not internalist about cognition. A source of tension between enactivism and HEC is that the latter assumes a computational-functionalist view of cognition that the former rejects. For HEC, cognitive processes are computational processes over representations. HEC's distinctive claim is that in some cases the relevant computational work is done over representations that are located not just in the brain or body, but also in the world - as when we rely on written numbers to perform complex calculations. Here, even if some representations are stored in the world, they are still part of the cognitive process, on the basis of a criterion of functional equivalence (also known as the "parity principle"; see Clark and Chalmers 1998). Enactivism, as we saw, offers a very different account of cognitionone that rejects computational functionalism in favour of a view of the mind based on a specific account of the organization of living systems. So the question here is whether and how enactivism, and not just computational functionalism, can offer a view of the mind that does not necessarily enclose its material vehicles within the head. As I shall argue, I think that this is possible.

We can identify two enactive responses to Wheeler's internalist charge. The first one emphasizes the relational nature of enactive cognition, and rejects Wheeler's accusation of 
internalism by retorting that cognition, as relational, strictly speaking has no location (see Di Paolo 2009: 19; Thompson and Stapleton 2009: 26; Thompson 2011: 218). Thompson and Stapleton (2009: 26) elaborate on this point by noting a parallel with the phenomenological notion of intentionality: "Intentionality is always a relation to that which transcends the present state of the system ... In saying that the mind is intentional, phenomenologists imply that the mind is relational". They draw on Heidegger to note that "a living being is 'in' its world in a completely different sense from that of water being in a glass" (ibid.). I do not find this reply satisfying because, it seems to me, to the extent that enactivism posits the existence of mind-enabling material processes or vehicles (and does not just characterize mentality at a phenomenological-existential level), it cannot entirely sidestep the question of which and where these processes are. Thompson $(2011: 218)$ writes that "it does not make sense to think of cognition as spatially located in the way that the 'vehicles' enabling cognitive processes are spatially located", but HEC and the debate around it are precisely about the location of such vehicles. Unless enactivism intends to reject the idea of material vehicles of the mind altogether, it seems possible to talk about their location within an enactivist framework. ${ }^{10}$

In the rest of my discussion I then focus and elaborate on another enactive response to Wheeler's charge. This response, found in Di Paolo (2009), emphasizes that enactivism allows life to "extend" (Di Paolo's term), more specifically that it allows organisms to integrate "mediating structures" into their (precarious) adaptive autonomous organization. Di Paolo offers the example of aquatic insects that can breathe underwater by trapping air bubbles on their tiny abdominal hairs (plastrons). ${ }^{11}$ As the insect consumes the oxygen

${ }^{10}$ Radical enactivists (Hutto and Myin 2013) do reject the notion of "vehicles" of cognition, together with the one of "content", because they see both notions as going hand-in-hand with computational-representationalist accounts of cognition. However, it is not clear that canonical enactivism needs to reject all talk of vehicles and contents. This is a point that promoters of canonical enactivism will need to clarify in the future. Here I only note that Thompson (2007: 59) seems willing to talk of "vehicles" in the sense of "the structures or processes that embody meaning", provided we keep in mind that these are "temporally extended patterns of activity that can crisscross the brain-body-world boundaries, and the meanings or contents they embody are brought forth or enacted in the context of the system's structural coupling with its environment".

11 There are several species of aquatic insects, commonly called "water boatmen", that use this or other similar underwater respiration methods. Di Paolo refers to Thorpe's (1950) 
contained in these bubbles, a partial pressure deficit is created in them, which is then compensated by dissolved oxygen that diffuses in from the water, so that the process can continue indefinitely. Di Paolo characterizes this as a new form of life involving a structure (the air bubbles) that mediates the organism's regulatory activity of its coupling (i.e., reciprocal interactions) with the environment. As he notes, "the mediation in cases like this is so intimately connected with vital functions that the living system itself might be called extended" (2009: 17). "Intimate connection" refers here to the integration or assimilation of the mediating structure into a new adaptive autonomous system - the system "insect-plus-airbubbles". This is a system underdetermined by metabolism, but it is a (new) form of life in that its structure exhibits the proper organization. This is tantamount to saying that the air bubbles are not external to the living form, merely allowing the insect to stay alive underwater; they are, rather, constitutive parts of the new form of life.

We can find innumerable other cases in nature of mediating structures that are intimately connected with vital functions. Consider for example the many microbes-prions, plasmids, organelles, etc. - that reside in complex organisms and contribute to a variety of functions, including gene expression and the maintenance of cell function (see Dupré and O’Malley 2009). According to Dupré and O'Malley, life indeed ought to be seen as a collaborative phenomenon that includes a multitude of micro-organisms coupled to the organism (traditionally understood). Note that Dupré and O'Malley present their view as diverging from traditional accounts of living systems that characterize them in terms of autonomy; in their opinion, the dependence of biological individuals on symbiotic associations with many other micro-organisms makes such an emphasis on autonomy problematic. Yet, as we saw, enactivism characterizes autonomy in terms of operational closure, which does not entail that living systems have to be identified via their physical boundaries; rather, living forms are individuated by "operational boundaries", i.e., boundaries established by relations of reciprocal influences among components (such that, as we saw, the results of the operations of the various components of the system remain within the system, thus forming a closed network). As such, operational boundaries need not coincide with physical boundaries (although they might, as in the case of the cell). A consequence of this account is that an operationally closed organization can be realized physically in a variety of ways, including ways that do not require the generation of a membrane (recall that, for

study, which described amongst others the genus Aphelocheirus, which apparently has perfected this system of respiration. 
enactivism, ant colonies and nervous systems count as autonomous systems). Thus, from an enactive perspective, symbiotic associations of the kind Dupré and O'Malley discuss are best understood as generating new adaptive autonomous structures - new forms of life that are "extended" relative to the traditional conception of the organism.

Note that something like the idea of an "extended organism" can be found already in the original formulation of the theory of autopoiesis. Maturana and Varela (1980: 107-111) discussed "higher-order" autopoietic systems. These are composite autopoietic systems, i.e., autopoietic systems constituted by either (i) two or more coupled autopoietic systems - as in the case of "the multicellular pattern of organization" (110); or (ii) one or more autopoietic systems coupled to non-autopoietic systems. In composite autopoietic systems, the component autopoietic systems are subordinated to the maintenance of the higher-order autopoietic unity. The only difference between (i) and (ii) is that in (ii) the non-autopoietic system, as such, does not have the capacity autonomously to maintain its identity; nevertheless, it still participates in the autopoietic organization of the higher-order unity. The subordinate component autopoietic system (or systems), because of its coupling with a non-autopoietic system, undergoes structural changes but maintains its autopoietic organization, and at the same time becomes a constituent part of a different and larger autopoietic system. In what follows, I shall adopt the terminology of "composite" systems to refer to adaptive autonomous (rather than autopoietic) systems constituted by two or more coupled adaptive autonomous systems, or one or more adaptive autonomous systems coupled to non-autonomous ones. The system composed by the aquatic insect and the air bubbles trapped on its hair is an instance of the latter.

\section{Extending sense-making}

If the preceding analysis is correct, then the enactive approach does not entail that living beings are necessarily bounded by the organism's skin (or other material boundary). Living beings can be "extended", as in the case of composite systems made of organic and nonorganic processes. I now want to draw out some of the implications of this point that so far have remained implicit in the enactive approach. In particular, in this section I first elaborate the claim that cognition as sense-making can also extend - in the sense that it can be brought forth by hybrid organic/non-organic composite systems. Then I elaborate the point that, because sense-making is also inherently affective (as we saw), affectivity as well can extend. 
Let us stay with the example of aquatic insects. Recall that the enactive notion of sense-making refers to the living organism's activity of enacting or bringing forth a world of significance (an Umwelt) in virtue of the organism's (precarious) adaptive autonomy. So what about, say, a diving beetle? As a living being, it is a sense-making system that enacts a certain Umwelt characterized by a graded landscape of values. This is the case both when the beetle walks on the ground, and when it dives underwater into a pond. In the latter case, the air bubbles that the beetle traps on its hair are a mediating structure integrated into a new type of agent (a new form of life). Here the underwater Umwelt of the beetle is enacted thanks to the mediation of the air bubbles, as these are integrated into the new adaptive autonomous structure. As such, the underwater beetle (in effect, the composite system beetle-plus-airbubbles) brings forth a new (compared to the beetle-on-the-ground, or the underwater-beetlewith-no-air-bubbles) set of norms for self-maintenance. In enactive terminology, this is the same as saying that the underwater beetle makes sense of, or cognizes, the world in a new way.

We can illustrate this point with a comparison. The Umwelt of the diving beetle is quite different from the one of a non-aquatic insect that happens to find itself underwater. A non-aquatic ant, for example, can survive underwater for some time by reducing its oxygen intake and by closing its spiracles to keep water off. Unlike plastron respiration, this strategy cannot go on indefinitely. The same pond thus has a different value for the submerged ant than it has for the diving beetle. For the ant, the pond invites a certain protective behaviour; it is a threatening environment, one that needs to be left. For the beetle, it is a comfortable, even enticing, environment where it can thrive and choose to dwell. This is another way of saying that the ant and the beetle enact different worlds, i.e., they make sense of, or cognize, their surroundings in different ways. Importantly, this difference depends on the integration, within the organization of the beetle, of the air bubbles; in this sense, we have here a case of “extended sense-making".

Given the affective nature of sense making (see section 2) we also, then, have a case of "extended affectivity". The different affective character of the Umwelt enacted by the ant and the beetle respectively should be apparent by now. I said that the pond is "threatening" to the ant, and "comfortable" and "enticing" to the beetle. In other words, the pond affects (strikes as significant) the diving beetle differently from how it affects the ant. We can also say that, correlatively, the underwater ant wants to get away from the pond and is frightened, worried, defensive, whereas the beetle does not want to get away from the pond, and is comfortable and confident in it. Unlike the ant's, the beetle's affective condition (of 
confidence) is extended, in the sense that it is realized by the composite hybrid system "beetle-plus-air-bubbles".

A useful way of characterizing the affective nature of this scenario in some more detail at the phenomenological level is in terms of the different affordances that the pond offers to the submerged ant and beetle respectively. As is well known, the notion of affordance was introduced by Gibson (1979) and is central to ecological psychology. It refers to possibilities of action offered by the environment to an organism. What the environment affords, in this sense, to any specific organism, depends on the latter's sensorimotor structure and abilities. To organisms like us, a chair, for example, typically affords sitting on (whereas it affords jumping on or scratching to a cat, crawling up to an ant, etc.); a flight of stairs affords stepping up and down, and so on.

Now, affordances have been referred to primarily to account for the active nature of (mainly visual) perception. However, talk of affordances can also help characterize the affective nature of our lived environments. An organism's Umwelt can be seen as a landscape of valued objects and events that invite to relate to them in different ways - not just motorically, but also psychologically, as forces that "attract" or "repel" in an affective sense (see also Dreyfus and Kelly 2007; Withagen et al. 2012). Thus, for example, a predator is something that compels the organism to run away, but also a desire to keep a distance, to stay away. Similarly, a source of food affords the action of moving towards it, but also a desire to ingest the item, and more generally a state of enticement and attraction. Again, this idea can be found already in Jonas (1966). In his comparison of vegetable life with animal life, he pointed out that whereas in the case of plants the organism and the world are contiguous (the plant takes what it needs directly from the soil, the air, and the sunlight), animal life is characterized by a distance between the organism and what it needs (e.g., food) or what it needs to avoid (e.g., predators). This distance is not just spatial, it is also temporal: the animal is here and the food it needs is over there, hence the animal now does not have that food. For Jonas, whereas in the history of life spatial distance is at the origin of perception and action, temporal distance is at the origin of emotion. Because spatial distance always also implies a temporal distance, in animals perception, action and emotion are linked and always present together. The animal needs sensory organs to perceive distant sources of food and potential predators. To fill the distance between itself and the food, the animal needs to move toward the food, but it also needs to keep wanting the food; similarly, to keep the distance between itself and a chasing predator, it needs to move away from it but also to keep wanting to do so. 
Jonas (1966) calls this prolonged desire an "emotional intent", and sees more specific emotions as manifestations of it:

The very span between start and attainment ... must be bridged by continuous emotional intent. The appearance of directed long-range motility (as exhibited by the vertebrates) thus signifies the emergence of emotional life. Greed is at the bottom of the chase, fear at the bottom of flight. (101)

This important idea can be found also in the work of the social psychologist Kurt Lewin (e.g., Lewin 1935), who described the lived environment as a landscape of "imperative environmental facts" (77) that prompt or stimulate the organism to act and feel in a variety of ways. ${ }^{12}$ These imperative environmental facts create a "field of forces" that constitute the world for the agent not just as a physical world but as a psychobiological environment. The latter always depends, in each moment, on the needs of the organism. Interestingly, long before the introduction of the English notion of affordances, Lewin had characterized these imperative environmental facts as Aufforderungscharaktere, which the translators chose to render as "demand characters" or "valences" (now a key term in affective science; see Colombetti 2005). The term could just as well be translated as "affordance characters", as the verb auffordern in German means to "prompt", "invite" or "stimulate". In any case, the important point is that Lewin already emphasized that an organism's psychobiological environment does not just prompt or afford certain kinds of motor actions (such as sitting, grasping, pinching), but also affective states of attraction and repulsion (including mixtures of the two). These affective states do not always coincide with behaviour of approach or withdrawal, respectively: "When the child fetches a tool or applies to the experimenter for help, the action does not mean, even when it involves a physical movement in a direction opposite to the goal, a turning away from the goal but an approach to it" (Lewin 1935: 84). The attractive or repelling character of items in the environment always depends, for Lewin, on the organism's state of "tension" and what it needs at each moment, such that the same

12 Equivalent notions can be found in Tolman (1932), Uexküll (1934/2010), and Koffka (1935). 
physical space can have very different demand characters for organisms with different needs. $^{13}$

Going back to our submerged ant and beetle, we can now say that their Umwelten differ in what they afford, or better in the "field of forces" they exhibit. The Umwelt of the ant has mostly a repelling demand character, which the Umwelt of the system beetle-plus-airbubbles lacks; the Umwelt of the beetle-plus-air-bubbles has an attractive demand character. In both cases, each Umwelt will also be structured further in a finer-grained way, containing areas of attraction (such as sources of food and specific levels of water pressure) and more repelling areas (other levels of water pressure, toxins, predators, etc.). These demand characters will be experienced not just in terms of "tendencies to move" in one way or another, but also in terms of psychological tensions away from or towards aspects of the environment. For present purposes, the point of interest is that, in the case of the underwater beetle, the demand characters of its Umwelt are brought forth by the composite system beetleplus-air-bubbles. Take the air bubbles away from the underwater beetle, and its Umwelt rapidly takes on a different profile of demand characters, with many lines of force reversing their direction and repelling the insect from the pond. The addition of a mediating structure changes the psychobiological environment of the beetle, thus also changing its affective condition.

It is important to emphasize that the proposal here is not that the mediating structure simply "enables" a new or altered affective state, but that it constitutes it. We saw in the previous section that mediating structures that are integrated into a new adaptive autonomous organization or form of life are not simply enabling but constitutive of the latter. This logic is maintained when it comes to sense-making, and thus to cognition as well as affectivity. The proposal here is that mediating structures that extend a living system into a new form of life are also mediating structures that extend affectivity - in the sense that they extend the material processes or vehicles that underpin sense-making, and thereby affective episodes.

\footnotetext{
${ }^{13}$ Gibson (1979) mentions Lewin's notion of demand character as a precursor of his notion of affordances, but also emphasizes a main difference between the two: unlike Lewin's demand characters, Gibson's affordances do not depend on the organism's needs (op. cit., 129-131). Relatedly, Gibson also claims that affordances should be characterized in terms of behaviour and biology, rather than experience or phenomenology. I think this claim is problematic, although I shall not develop this point here. See also Dreyfus and Kelly (2007) for a phenomenological take on affordances.
} 
The affective condition of the diving beetle is extended in that its vehicles have integrated mediating structures into a new form of life. The mediating structure is now part of the material processes that realize a new cognitive-affective sense-making activity. ${ }^{14}$

\section{Extending moods}

The discussion so far has focused on affectivity broadly characterized, and on how it can be realized by simple extended living systems. In this final section I briefly and tentatively start to consider whether and how, from an enactive perspective, specific human affective states may also extend. I focus in particular on moods - such as having the blues, being down, being elated, cranky, up or down. I suggest that it is possible, at least sometimes, to regard these episodes, enactively construed, as underpinned by composite systems made of organic and non-organic processes.

Let us begin by noting that, at the subpersonal level, enactivism characterizes moods dynamically as global self-organizing patterns of the organism, with a specific topology of attractors, each of which corresponds to a specific emotional state (Lewis 2000; Thompson 2007: 378-380; Colombetti 2014: 77-82). In other words, when a person is in a certain mood, its organism is in a global state that makes it more likely to assume the (neural, physiological, and expressive) profile characteristic of some emotional states rather than that of others. For

${ }^{14}$ Some readers will find this constitutive claim counterintuitive. One referee queried why I did not settle for the "more intuitive" view that the air bubbles causally support, or scaffold, both living and affective processes (but are not themselves part of the living system). The answer is that it is not the goal of this paper to settle the causal-constitution debate. This paper is structured so as to draw out logically (what I think are) the implications of the enactive approach for the material underpinnings of affectivity. As explained in the previous section, I think that enactivism's characterization of life entails that living systems can extend, i.e., that appropriately integrated mediating structures can be part of living systems. My further point in this and the next section is that, if enactivism entails that life extends, then it also entails that affectivity extends. Personally, I do not find these claims counterintuitive, but in any case intuitions should not matter here, because in this paper the constitutive claims are derived logically as implications of enactivism's characterization of life and sense-making. In other words, the arguments of this paper should be construed as a conditional: given enactivism's account of life and cognition, it follows that affectivity can extend. 
example, someone in an irritable mood is more likely to be entrained into a state of anger than someone in a joyful mood, who on his part is more likely to be entrained into a state of happiness or amusement. Phenomenologically, the enactive approach characterizes moods as experiential states that, unlike emotions, are not directed at any specific (nor, for that matter, "general") object, but are nevertheless open to the world (see Thompson and Zahavi 2007 for this broad sense of intentionality; see also Colombetti 2014, chap. 3). A depressed mood, for example, is not about anything in particular, but it still comes with an appearance of the world as flat, oppressive, deprived of possibilities. Different moods come with different appearances of the world (in irritability, the world is obstructive, in the way, annoying; in optimism, the world is enticing, wide, enabling, etc.). This openness is the condition of possibility for having emotions, namely affective states with specific intentional objects (see also Ratcliffe 2010, whose work is inspired by Heidegger's account of mood).

Given this account, what could count as "extended moods"? I suggest that they would be all those instances of mood realized by a composite adaptive autonomous system involving an organism and either (i) an extra-bodily item, or (ii) another organism (or other organisms), or (iii) a combination of these. Case (ii) has already been explored in the enactive approach and has been dubbed participatory sense-making (De Jaegher and Di Paolo 2007). Participatory sense-making is sense-making realized by a higher-order adaptive autonomous system resulting from the coupling of one or more sense-making systems. Thus two human beings engaged in reciprocal postural adjustments as they strive to walk past each other in a narrow corridor are coupled (mutually influencing) and together instantiate a system that has its own adaptive autonomous organization. This latter system is characterized by its own modality of sense-making, and as such counts as an extended cognitive-affective system.

Much more could be said about affectivity in coupled systems of this kind (see for example Krueger 2013 for the idea that emotions can be "jointly owned"). My aim here, however, is to consider how moods can be extended via the integration, into their vehicles, of non-organic mediating items (case (i) above). For a start, consider the case of the (solo, for now) improvising jazz musician, and more specifically an instrumentalist, e.g., a saxophone player. As Cochrane (2008) has argued, we should think of the musician and his saxophone as coupled: as the musician improvises, he makes some changes to the instrument (presses keys, breathes air into it), which produce sounds, which influence what the musician plays next, and so on. We can say that it is thus in the act of playing, through the (temporally extended) interaction with the instrument, that the musician (or rather, the system musician-plusinstrument) achieves a certain mood. The saxophone can be seen as a mediating structure that 
has become part of the adaptive autonomous organization of a new, higher-order composite system constituted by the musician and his instrument (in other words, the relationship is analogous to the one between the underwater beetle and its air bubbles). In particular, we can say that this is an "extended mood" because the saxophone has become integrated within the network of physical processes that realize the topology that determines the kind of emotional states the system is more likely to get into. We can imagine, for example, that improvising on the saxophone realizes a mood of longing that makes the system more likely to undergo an emotion of nostalgia for a specific person or moment of life. As the musician plays, the network of processes that realize the relevant topology is the composite system made up by his brain, body, and instrument. ${ }^{15}$

\section{Final considerations and questions for the future}

In this paper I have argued that the enactive approach has room for extending both cognition and affectivity. Specifically, I have argued that if life, enactively characterized, can extend (as suggested by Di Paolo 2009), then so can sense-making, which is simultaneously cognitive and affective. I have also briefly suggested that enactivism allows specific human affective states, such as moods, to extend. Overall, I have thus delineated one possible sense in which affectivity is not enclosed within the organism.

This analysis should be taken as preliminary as there are several questions that still need to be addressed to establish whether and how an enactive perspective can challenge internalist accounts of affectivity. Addressing these questions will require enactivists to clarify and develop a variety of issues. For example, a question I did not address here concerns whether and how enactivism allows for the extension of human emotional states, which are typically characterized as intentional states about specific objects (I am afraid of the dog, angry at John, etc.). Answering this question would require discussing and elaborating on enactivism's treatment of the notion of intentionality (see Thompson 2007: 22-27). Further consideration needs to be given to how extra-bodily items that are integrated into a new form of life are experienced: are they phenomenologically "incorporated", i.e. experienced like other parts of one's own body (see Merleau-Ponty 1945/2012)? If so, what does this experience amount to? Does it require a sense of ownership, or only a feeling of "extension"

${ }^{15}$ For related discussions of this example, see Colombetti and Roberts (2015) and Roberts (2015). 
(see discussion in De Preester and Tsakiris 2009)? Does it require "caring" or "feeling concern" for the mediating object in the same way as we care or feel concern for our bodily parts? And what exactly should be the role of phenomenological considerations in establishing whether a non-organic object is part of an affective state? In this paper I have developed phenomenological considerations to describe the lived perspective of organisms, with the aim of characterizing the phenomenon of "extended sense-making" in some detail. But I have not offered phenomenological considerations as criteria for extending sensemaking; the criterion I have advanced is rather empirical, as it requires to look at the details of the material organization of a hybrid organic/non-organic system to establish whether it realizes precarious adaptive autonomy. Yet enactivists such as Thompson take phenomenology to be not just a descriptive but also a transcendental enterprise, whose role is to disclose the conditions of possibility of experience, through which to make sense of empirical observations (e.g., Thompson 2007: 239-240). So perhaps phenomenology should play a more important role in enactivist arguments about the non-internal nature of mind and affectivity (Thompson and Stapleton 2009 appear to favour this strategy). ${ }^{16}$ Relatedly, the informed reader may have noted that there is a tension between the arguments put forward in this paper, and the point, made by Thompson and Stapleton (2009: 25), that enactivism is "neither internalist nor externalist" because "the internalist/externalist debate rests on assumptions that are foreign to the enactive approach". As briefly mentioned earlier (section 3), I think that this claim needs elaboration, in particular one question for the future is whether enactivism needs to reject all talk of "vehicles" of mental states (as Hutto and Myin 2013 for example recommend). In this paper I have taken enactivism to be compatible with the notion of vehicles, broadly understood to refer to the physical processes that underpin (enact) mental activity.

In any case, for now, I hope that the considerations advanced here will stimulate discussion and additional elaborations of the enactive approach, further clarifying the latter's stance toward recent accounts of how the mind relates to the world.

\section{ACKNOWLEDGEMENTS}

16 See also Zahavi (2011) for related questions about the role of phenomenology in enactivism, and its relation to natural science. 
I am grateful to participants of the AISB 2014 symposium on enactivism, and to Ezequiel Di Paolo, Tom Roberts, and two anonymous referees for their comments on early versions of this paper. Any remaining misunderstanding is entirely my responsibility. This work was partially supported by the European Research Council under the European Community's Seventh Framework Programme (FP7/2007-2013), project title "Emoting the Embodied Mind" (EMOTER), ERC grant agreement 240891.

\section{REFERENCES}

Clark, A. (2003). Natural-born cyborgs: Minds, technologies, and the future of human intelligence. Oxford: Oxford University Press.

Clark, A. (2008). Supersizing the mind: Embodiment, action, and cognitive extension. Oxford: Oxford University Press.

Clark, A., \& Chalmers, D. (1998). The extended mind. Analysis, 58, 7-19.

Cochrane, T. (2008). Expression and extended cognition. The Journal of Aesthetics and Art Criticism, 66(4), 329-340.

Colombetti, G. (2005). Appraising valence. Journal of Consciousness Studies, 12(8-10), 103126.

Colombetti, G. (2014). The Feeling Body: Affective Science Meets the Enactive Mind. Cambridge, MA: MIT Press.

Colombetti, G., \& Roberts, T. (2015). Extending the extended mind: the case for extended affectivity. Philosophical Studies, 172(5), 1243-1263.

Damasio, A. R. (1999). The Feeling of What Happens: Body, Emotion and the Making of Consciousness. London: Vintage.

De Jaegher, H., \& Di Paolo, E. A. (2007). Participatory sense-making: An enactive approach to social cognition. Phenomenology and the Cognitive Sciences, 6, 485-507.

De Preester, H., \& Tsakiris, M. (2009). Body-extension versus body-incorporation: Is there a need for a body-model? Phenomenology and the Cognitive Sciences, 8(3), 307-319.

Di Paolo, E. A. (2005). Autopoiesis, adaptivity, teleology, agency. Phenomenology and the Cognitive Sciences, 4, 429-452.

Di Paolo, E. A. (2009). Extended Life. Topoi, 28(1), 9-21.

Di Paolo, E. A., \& Thompson, E. (2014). The enactive approach. In L. A. Shapiro (Ed.), The Routledge Handbook of Embodied Cognition (pp. 69-77). Oxon: Routledge.

Dreyfus, H., \& Kelly, S. D. (2007). Heterophenomenology: Heavy-handed sleight-of-hand. 
Phenomenology and the Cognitive Sciences, 6(1-2), 45-55.

Dupré, J., \& O’Malley, M. A. (2009). Varieties of living things: life at the intersection of lineage and metabolism. Philosophy and Theory in Biology, 1:e003.

Gibson, J. J. (1979). The Ecological Approach to Visual Perception. Boston, MA: Houghton, Mifflin and Company.

Hurley, S. (2010). The varieties of externalism. In R. Menary (Ed.), The extended mind (pp. 101-153). Cambridge, MA: MIT Press.

Hutto, D. D., \& Myin, E. (2013). Radicalizing enactivism: basic minds without content. Cambridge, MA: MIT Press.

James, W. (1884). What is an emotion? Mind, 9, 188-205.

Jonas, H. (1966). The Phenomenon of Life: Toward a Philosophical Biology. Northwestern University Press.

Koffka, K. (1935). Principles of Gestalt Psychology. London: Routledge and Kegan Paul.

Krueger, J. (2013). Merleau-Ponty on shared emotions and the joint ownership thesis. Continental Philosophy Review, 46, 509-531.

Lewin, K. (1935). A Dynamic Theory of Personality: Selected Papers. (D. K. Adams \& K. E. Zener, Trans.). New York: McGraw-Hill.

Lewis, M. D. (2000). Emotional organization at three time scales. In M. D. Lewis \& I. Granic (Eds.), Emotion, Development, and Self-Organization: Dynamic Systems Approaches to Emotional Development (pp. 37-69). Cambridge: Cambridge University Press.

Maturana, H. R., \& Varela, F. J. (1980). Autopoiesis and Cognition: The Realization of the Living. Dordrecht: D. Reidel.

Menary, R. (Ed.). (2010). The extended mind. Cambridge, MA: MIT Press.

Merleau-Ponty, M. (1945/2012). Phenomenology of Perception. (D. A. Landes, Trans.). New York: Routledge.

Noë, A. (2004). Action in Perception. Cambridge, MA: MIT Press.

Nussbaum, M. C. (2004). Emotions as judgments of value and importance. In R. C. Solomon (Ed.), Thinking About Feeling: Contemporary Philosophers on Emotions (pp. 183199). New York: Oxford University Press.

Prinz, J. J. (2004). Gut feelings: A perceptual theory of emotion. Oxford: Oxford University Press.

Ratcliffe, M. (2010). The phenomenology of mood and the meaning of life. In P. Goldie (Ed.), The Oxford Handbook of Philosophy of Emotion (pp. 349-371). Oxford: Oxford University Press. 
Roberts, T. (2015). Extending emotional consciousness. Journal of Consciousness Studies, $22(3-4), 108-128$.

Solomon, R. C. (1993). The Passions: Emotions and the Meaning of Life (2nd Revised edition edition). Indianapolis: Hackett.

Stephan, A., Walter, S., \& Wilutzky, W. (2014). Emotions beyond brain and body. Philosophical Psychology, 27(1), 98-111.

Thompson, E. (2007). Mind in Life: Biology, Phenomenology, and the Sciences of Mind. Cambridge, MA: Harvard University Press.

Thompson, E. (2011). Reply to commentaries. Journal of Consciousness Studies, 18(5-6), $176-223$.

Thompson, E., \& Stapleton, M. (2009). Making Sense of Sense-Making: Reflections on Enactive and Extended Mind Theories. Topoi, 28(1), 23-30.

Thompson, E., \& Zahavi, D. (2007). Philosophical issues: Continental phenomenology. In P. D. Zelazo, M. Moscovitch, \& E. Thompson (Eds.), The Cambridge Handbook of Consciousness (pp. 67-88). Cambridge: Cambridge University Press.

Thorpe, W. H. (1950). Plastron respiration in aquatic insects. Biological Reviews, 25, 344390.

Tolman, E. C. (1932). Purposive Behavior in Animals and Men. New York: AppletonCentury.

Uexküll, J. von. (1934). A Foray into the Worlds of Animals and Humans. With a Theory of Meaning. (J. D. O’Neil, Trans.). Minneapolis and London: University of Minnesota Press.

Varela, F. J. (1979). Principles of Biological Autonomy. New York: Elsevier.

Varela, F. J. (1991). Organism: A meshwork of selfless selves. In A. I. Tauber (Ed.), Organism and the origin of the self (pp. 79-107). Kluwer Academic Publishers.

Varela, F. J., \& Depraz, N. (2005). At the source of time - Valence and the constitutional dynamics of affect. Journal of Consciousness Studies, 12, 61-81.

Varela, F. J., Thompson, E., \& Rosch, E. (1991). The Embodied Mind: Cognitive Science and Human Experience. Cambridge, MA: MIT Press.

Weber, A., \& Varela, F. J. (2002). Life after Kant: Natural purposes and the autopoietic foundations of biological individuality. Phenomenology and the Cognitive Sciences, $1(2), 97-125$.

Wheeler, M. (2010). Minds, Things and Materiality. In L. Malafouris \& C. Renfrew (Eds.), The cognitive life of things: recasting the boundaries of the mind (pp. 29-37). 
Cambridge: McDonald Institute for Archaeological Research.

Withagen, R., de Poel, H. J., Araújo, D., \& Pepping, G.-J. (2012). Affordances can invite behavior: Reconsidering the relationship between affordances and agency. New Ideas in Psychology, 30(2), 250-258.

Zahavi, D. (2011). Mutual enlightenment and transcendental thought. Journal of Consciousness Studies, 18(5-6), 169-175. 